(C) Elsevier Sequoia S.A., Lausanne - Printed in The Netherlands

\title{
INITIAL STAGES OF ANODIC OXIDATION OF SILVER IN SODIUM HYDROXIDE SOLUTION STUDIED BY POTENTIAL SWEEP VOLTAMMETRY AND ELLIPSOMETRY
}

JOHN M.M. DROOG, PETER T. ALDERLIESTEN and GOSSE A. BOOTSMA

Van 't Hoff Laboratory, State University of Utrecht, Padualaan 8, Utrecht (The Netherlands)

(Received 15th September 1978)

\section{ABSTRACT}

The first stages of the oxidation of polycrystalline silver electrodes in $\mathrm{NaOH}$ solutions were studied by potential sweep voltammetry and ellipsometry. Formation of bulk $\mathrm{Ag}_{2} \mathrm{O}$ was found to be preceded by dissolution of silver species and deposition of a surface oxide. The equilibrium oxide coverage depended on the electrode potential and occurred within a few seconds. Surface oxide formation probably took place via a process of random electrodeposition. No ageing effect was observed in the chemisorbed layer.

\section{(1) INTRODUCTION}

The use of silver oxide electrodes in storage batteries has stimulated many investigations of the anodic oxidation of silver in alkaline electrolytes. Nevertheless, much remains to be discovered about the oxidation mechanisms and the structure of the silver oxides formed. (See refs. 1-12 for reviews.)

Cyclic voltammograms (Fig. 1) generally show four peaks in the anodic direction (A1 to A4) and two in the cathodic direction (C3 and C4). A3 and $\mathrm{A} 4$ are related to the formation of $\mathrm{Ag}_{2} \mathrm{O}$ and $\mathrm{AgO}$ and $\mathrm{C} 4$ and $\mathrm{C} 3$ are assigned to reduction of $\mathrm{AgO}$ and $\mathrm{Ag}_{2} \mathrm{O}$, respectively [11, 13-27]. The small peak $\mathrm{A2}$ has been variously attributed to the formation of $\mathrm{AgOH}[13,15]$, to oxidation of adsorbed hydrogen [18], to preferential oxidation of an activated lattice $[19,25]$, and to the dissolution of silver as $\mathrm{Ag}(\mathrm{OH})_{2}^{-}$with diffusion of the product into the solution $[22,23]$.

The minor peak $\mathrm{A} 1$ has attracted relatively little attention. Stonehart and Portante $[15,16]$ took it to be an artefact arising from the method of metal fabrication, because this peak was not observed upon oxidation of silver, electrodeposited from a plating bath. Březina et al. [28], rather surprisingly, stated that at potentials which are 200 to $700 \mathrm{mV}$ more negative than that of the $\mathrm{A} 1$ peak, surface oxides are formed. According to them the A1 peak is related to formation of a larger amount of $\mathrm{Ag}_{2} \mathrm{O}$. Giles et al. [29] concluded from impedance studies that the initial step in the oxidation, at potentials negative to the reversible $\mathrm{Ag} / \mathrm{Ag}_{2} \mathrm{O}$ potential (140 mV vs. Argenthal, in $1 \mathrm{M} \mathrm{NaOH}$ ) is the formation of a soluble species $\mathrm{Ag}(\mathrm{OH})_{2}^{-}$which diffuses away from the electrode. They stated that this was followed by phase formation on the electrode which 


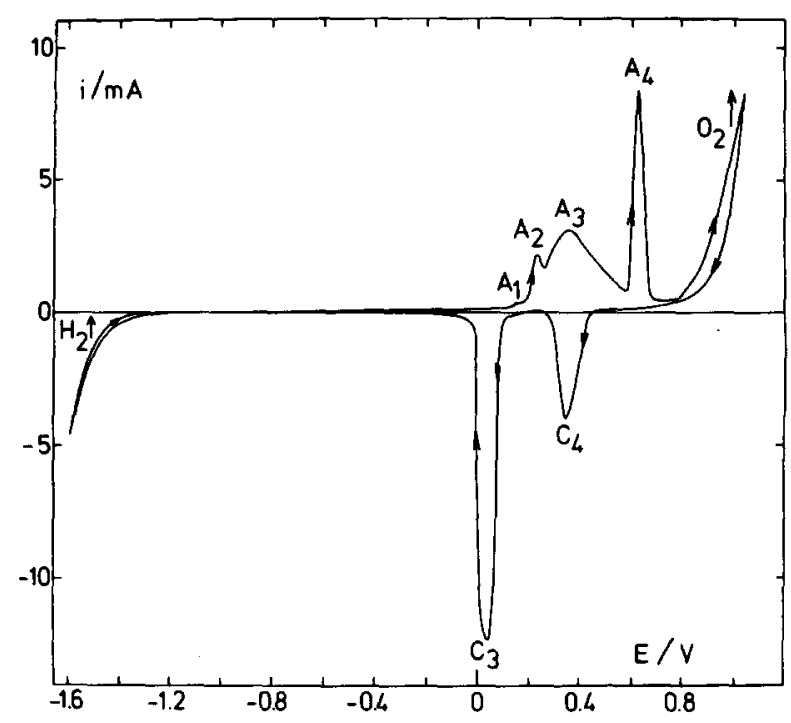

Fig. 1. Triangular sweep voltammogram for a silver wire in $1 M \mathrm{NaOH}$ after several oxidation and reduction cycles. $22^{\circ} \mathrm{C}, \mathrm{d} E / \mathrm{d} t=20 \mathrm{mV} \mathrm{s}^{-1}, E$ vs. "Argenthal" electrode (Ag/AgCl, $\mathrm{KCl}$ $(3 \mathrm{M}) / / ; E=207 \mathrm{mV}$ vs. NHE).

occurred first of all as a monolayer of $\mathrm{Ag}_{2} \mathrm{O}$ in the potential region of 130 to $180 \mathrm{mV}$. Above $180 \mathrm{mV}$ multilayer oxidation was said to occur. Giles and Harrison [30] also measured potentiodynamic curves. Their discussion of the results, however, has led to confusion $[22,25]$ because they compare their peak in the potential region of $\mathrm{A} 1$, with the $\mathrm{A} 2$ peak of other authors $[13,15,18,19]$. Tilak et al. [22] and Perkins et al. [23] associated the A1 peak with carbonate impurities in the solution. Ambrose and Barradas [27] concluded from ring disc experiments that in the region of peak $\mathrm{A} 1$, formation of soluble $\mathrm{Ag}(\mathrm{I})$ species occurs, probably in the form of $\mathrm{Ag}(\mathrm{OH})_{2}^{-}$species. The cathodic sweeps in their voltammograms with progressively increasing scan width did not indicate the presence of a surface layer, but the sensitivity of their measurements did not permit the detection of less than two monolayers. They considered it possible that a small shoulder in the anodic part of their voltammograms was due to monolayer formation.

The aim of the work reported here was to investigate further the first stages of silver oxidation in sodium hydroxide solutions, i.e. to assign the A1 peak in the voltammogram. It was expected that the technique of ellipsometry might give useful information, additional to that provided by electrochemical techniques.

\section{(2) EXPERIMENTAL}

The experiments were performed in a pyrex vessel ( $400 \mathrm{ml}$ capacity), equipped with pyrex windows, perpendicular to the light beam of the ellipsometer. Window-correction terms which were measured by the methods of Azzam and Bashara [31,32], turned out to be of the order of $0.2^{\circ}$ for $\Delta$ and $0.02^{\circ}$ for $\psi$, which, for relative measurements, is negligibly small. 
The ellipsometer was of the manual nulling type, and the compensator preceded the sample. The light source was a Spectra-Physics Model $120 \mathrm{He}-\mathrm{Ne}$ laser $(\lambda=632.8 \mathrm{~nm}$, output power $5 \mathrm{~mW})$, followed by a quarter-wave retardation plate to obtain circularly polarized light. A silicon photoelement (Siemens BPY 47) was used as light detector. The compensator retardation plate was a quarter-wave mica sheet and Zeiss micro-polaroid filters were applied as polarizer and analyser. The angle of incidence was $65 \pm 0.5^{\circ}$.

Transient measurements of $\Delta$ were obtained by light-intensity monitoring with the analyser in its extinction setting for the film-free surface, and the polarizer off-set from its null-position [33-35]. To check that changes in $\psi$ and in the reflectivity did not contribute to the light-intensity changes, measurements were done on both sides of the null position. For transient measurements of $\psi$ the analyser was off-set from its null position.

The working electrodes were silver discs (diameter $5 \mathrm{~mm}$, thickness $3-4 \mathrm{~mm}$ ) cut from a polycrystalline silver rod (Drijfhout, The Netherlands, $99.999 \%$ pure) and sealed into acrylic resin (Technovite 4071), in such a way that only the top surface of the metal was exposed to the solution. The electrodes were mounted on glass specimen holders, which were adjustable to allow proper alignment for the ellipsometer. The electrode surfaces were grazed with carborundum paper and polished with diamond pastes containing diamond particles as small as $0.25 \mu \mathrm{m}$ and then with alumina powders of particle sizes as small as $0.05 \mu \mathrm{m}$. After polishing, the electrodes were cleaned ultrasonically in twice-distilled water.

Before measurements, the specimen surfaces were cathodically reduced at $-500 \mathrm{mV}$ to remove any existing oxide films. In some cases the surfaces were also electropolished (Struers, Denmark, RP-1 electrolyte). Then, it was necessary to reduce cathodically the contaminating layer left from the electropolishing action by holding the conditions at the electrode surface at the point where hydrogen evolution was just beginning $(E=-1500 \mathrm{mV})$ [36-38]. Only with this pretreatment could reproducible current-voltage curves be obtained with the same shape and magnitude as those for the mechanically polished electrodes. An increase in the ellipsometric parameters $\Delta$ and $\psi$ indicated that a surface layer had been removed.

The counter electrode was a platinum plate (geometrical surface area 20 $\mathrm{cm}^{2}$ ), mounted parallel to the working electrode at a distance of $2 \mathrm{~cm}$, just outside the optical path. An Ingold "Argenthal" electrode (Ag/AgCl, $\mathrm{KCl}(3 \mathrm{M}) / /$; $E=207 \mathrm{mV}$ vs. NHE), separated from the main compartment, served as reference electrode. All potentials quoted in this paper are given with reference to this electrode.

The potential of the working electrode was controlled by means of a Wenking (LB 75L) potentiostat, fed by a voltage scan generator (Wenking VSG 72). Current-voltage characteristics were written on a XY recorder (Kipp BD 30 ) or on a storage oscilloscope (Tektronix $5103 \mathrm{~N}$ ). Integration of these $i / E$ curves was carried out either planimetrically, or with the help of an integrating digital voltmeter, composed of a voltage-to-frequency converter and a counter, with a digital-to-analog converter to allow direct plotting on the XY recorder. Solutions were prepared from carbonate-free $\mathrm{NaOH}$ (Baker, analytical reagent). The solutions were deaerated by bubbling with argon gas (purity $99.999 \%$ ) and 
during the measurements an argon atmosphere was maintained above the solutions. All measurements were performed at room temperature $\left(22^{\circ} \mathrm{C}\right)$.

\section{(3) RESULTS}

\section{(3.1) Cyclic voltammetry measurements}

(3.1.1) Effect of potential sweep limit. Typical cyclic voltammograms taken with a scan rate of $20 \mathrm{mV} \mathrm{s}^{-1}$ and increasing scan width for the potential region of the A1 peak are shown in Fig. 2. In the first stages of oxidation, the current drops almost immediately to cathodic values after reversal of the potential sweep, whereas at higher potentials of sweep reversal the current remains anodic for a while. Above a reversal potential of $125 \mathrm{mV}$ a cathodic peak begins to develop. In the anodic voltammogram a clear shoulder can be seen, with a strong rise in current at potentials above $190 \mathrm{mV}$. It should be noted that the anodic curves coincide exactly. However, when the potential is scanned too far into the $\mathrm{A} 2$ region (above circa $200 \mathrm{mV}$ ), then, in the next scan, the current is higher.

Current-voltage curves, integrated between $E=0 \mathrm{mV}$ and $E=E_{\mathrm{u}}$ (upper potential) are shown in Fig. 3 . It can be seen that the charge under the anodic curves $\left(Q_{a}\right)$ is larger than the charge under the cathodic curves $\left(Q_{c}\right)$, especially in the earliest stages of oxidation.

These charges are plotted vs. the potential of scan reversal in Fig. 4. Three
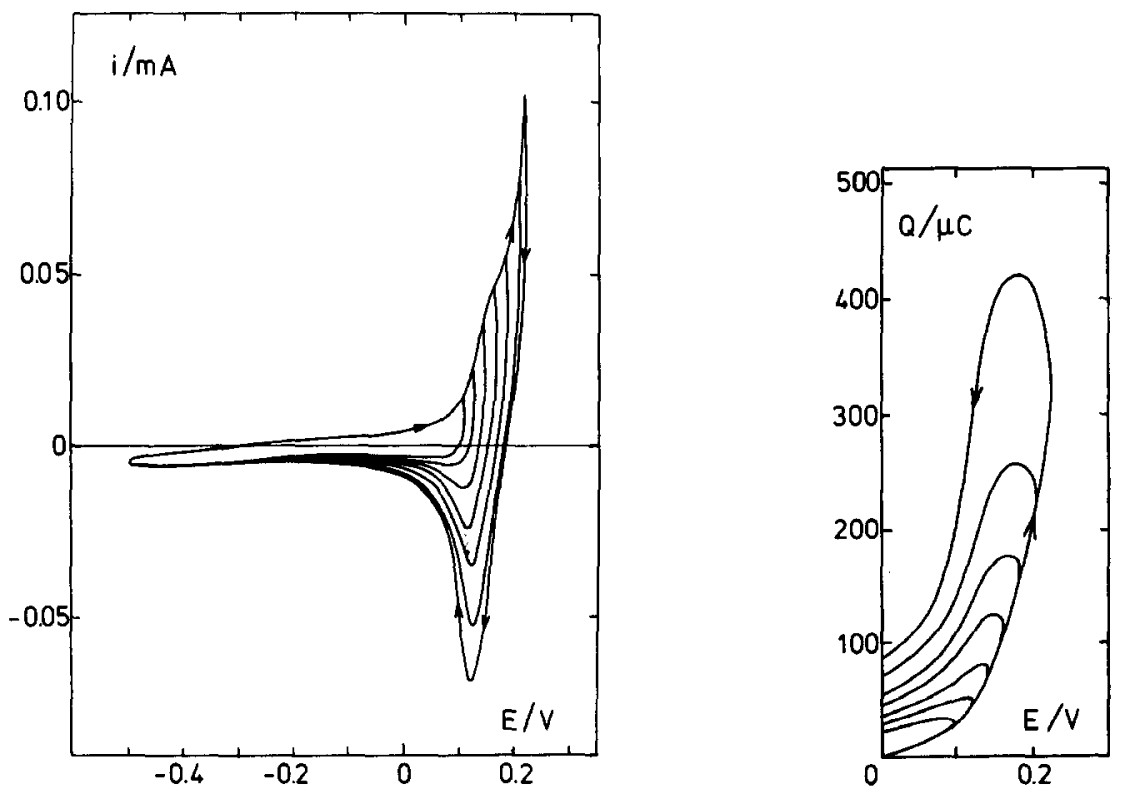

Fig. 2. Potentiodynamic charging curves for silver up to various potentials. $1 \mathrm{M} \mathrm{NaOH}, 22^{\circ} \mathrm{C}$, $\mathrm{d} E / \mathrm{d} t=20 \mathrm{mV} \mathrm{s}^{-1}$. Apparent surface area $0.2 \mathrm{~cm}^{2}$.

Fig. 3. Potential/charge curves for potential scanning of silver up to various potentials. $1 M$ $\mathrm{NaOH}, 22^{\circ} \mathrm{C}, \mathrm{d} E / \mathrm{d} t=20 \mathrm{mV} \mathrm{s}^{-1}$. 


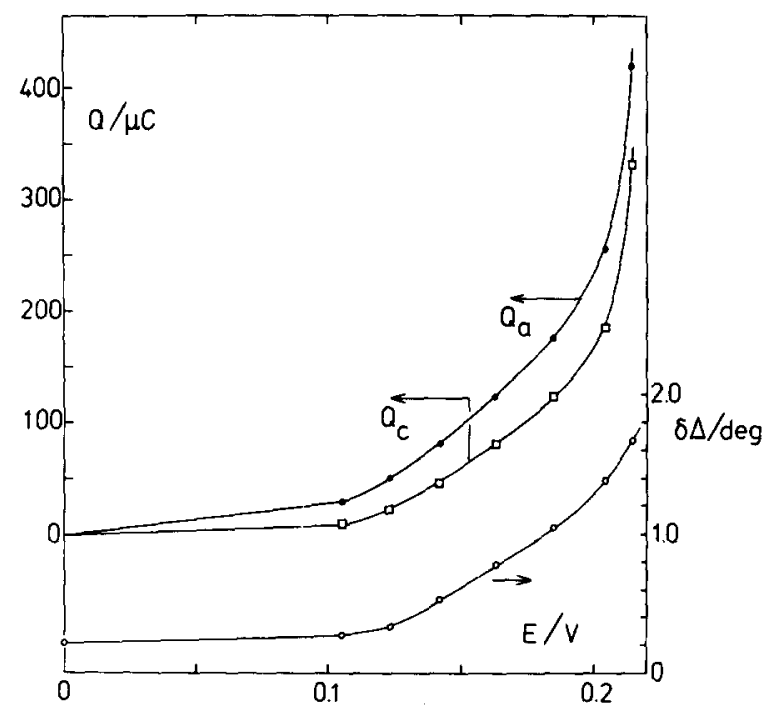

Fig. 4. Anodic charge $Q_{\mathrm{a}}$, cathodic charge $Q_{\mathrm{c}}$ and ellipsometric change $\delta \Delta$ vs. the potential of scan reversal. $\mathrm{Ag}$ in $1 M \mathrm{NaOH}, 22^{\circ} \mathrm{C}, \mathrm{d} E / \mathrm{d} t=20 \mathrm{mV} \mathrm{s}^{-1}$.

potential regions can be distinguished, the first is below about $100 \mathrm{mV}$, the second ranges from $100 \mathrm{mV}$ to about $200 \mathrm{mV}$ and the last is above $200 \mathrm{mV}$.

Figure 5 gives a typical example of the changes in the ellipsometric parameters $\Delta$ and $\psi$ as a function of the potential during a triangular sweep. The

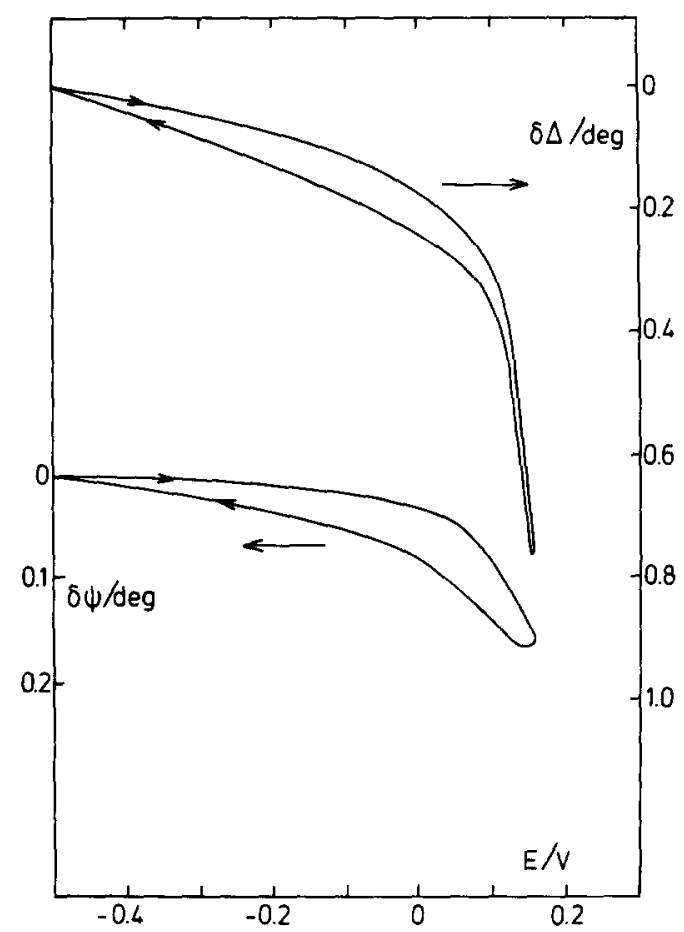

Fig. 5. Change in $\Delta$ and $\psi$ during potential scanning up to $160 \mathrm{mV}$. Ag in $1 \mathrm{M} \mathrm{NaOH}, 22^{\circ} \mathrm{C}$, $\mathrm{d} E / \mathrm{d} t=20 \mathrm{mV} \mathrm{s}^{-1}$. 


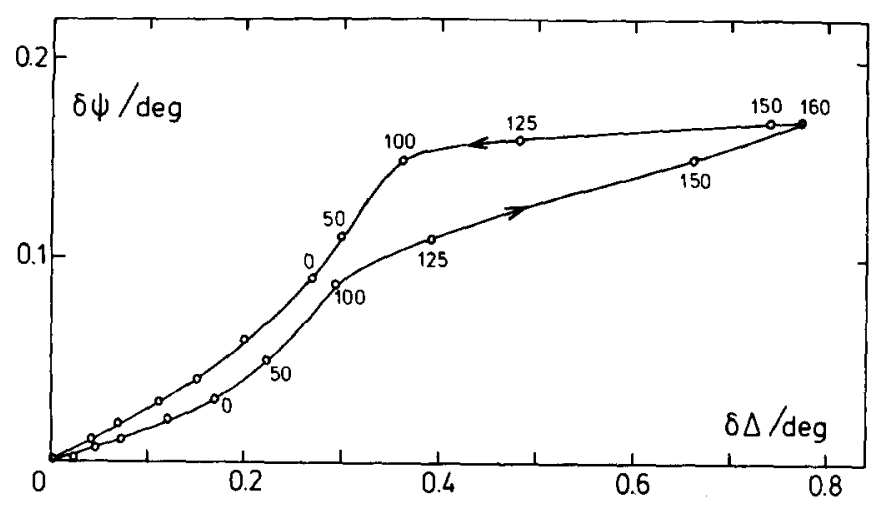

Fig. 6. $\Delta-\psi$ plot for potential scanning up to $160 \mathrm{mV}$. $\mathrm{Ag}$ in $1 \mathrm{MNaOH}, 22^{\circ} \mathrm{C}, \mathrm{d} E / \mathrm{d} t=20$ $\mathrm{mV} \mathrm{s}^{-1}$. Numbers in the Figure indicate potentials in $\mathrm{mV}$.

plotted parameters $\delta \Delta$ and $\delta \psi$ are defined by $\delta \Delta=\bar{\Delta}-\Delta$ and $\delta \psi=\bar{\psi}-\psi$, where $\bar{\Delta}$ and $\bar{\psi}$ represent the parameters for the bare silver substrate at -500 $\mathrm{mV}$. The values of $\bar{\Delta}$ and $\bar{\psi}$ were measured for eleven different electrodes. From these we calculated the optical constants of the pure silver, which proved to be $n=0.19 \pm 0.07$ and $k=3.80 \pm 0.22$.

Photo-effects have been reported for anodic oxidation of silver [17,20,23,29] and therefore the question arises whether the laser beam has any effect on the processes measured. We found that the cyclic voltammograms in the potential region of the $\mathrm{A} 1$ peak were exactly the same, whether the electrode was illuminated or not.

Figure 5 shows a sharp increase in $\delta \Delta$ just above $100 \mathrm{mV}$, whereas the change in $\psi$ is smaller and less abrupt. During the negative sweep the decrease in $\delta \Delta$ is very fast and already at $100 \mathrm{mV}, \delta \Delta$ has almost returned to its value at that potential during the anodic sweep. In Fig. 4 maximum values of $\delta \Delta$ are plotted vs. the potential of scan reversal.

A $\Delta-\psi$ plot of the curves in Fig. 5 is shown in Fig. 6. An important change in the slope of the curve is seen at about $100 \mathrm{mV}$, both in the positive and in the negative scan.

(3.1.2) Effect of sweep rate. Voltammograms were measured with sweep rates varying between $5 \mathrm{mV} \mathrm{s}^{-1}$ and $2000 \mathrm{mV} \mathrm{s}^{-1}$. Neither the anodic nor the cathodic peak currents are proportional to the sweep rate $s$ or to $s^{1 / 2}$. The peak potentials depend only slightly $(10-20 \mathrm{mV})$ on the sweep rate. In Fig. 7 the charges $Q_{\mathrm{a}}$ and $Q_{\mathrm{c}}$ are plotted for voltammograms measured at different sweep rates, with a starting potential of $-500 \mathrm{mV}$ and a potential of scan reversal of $180 \mathrm{mV}$. In the same Figure $\delta \Delta$ is plotted vs. $s$. It is quite clear that the dependence of $Q_{\mathrm{a}}$ and $Q_{\mathrm{c}}$ on $s$ is different from the dependence of $\delta \Delta$ on $s$.

(3.1.3) Effect of carbonate and of hydroxide concentration. To test the influence of carbonate impurities an experiment was performed with three different $1 M \mathrm{NaOH}$ solutions, namely a freshly prepared carbonate-free solution under argon atmosphere and two solutions with $0.01 M$ and $0.1 M \mathrm{Na}_{2} \mathrm{CO}_{3}$, respectively. No significant differences were found between cyclic voltammo- 


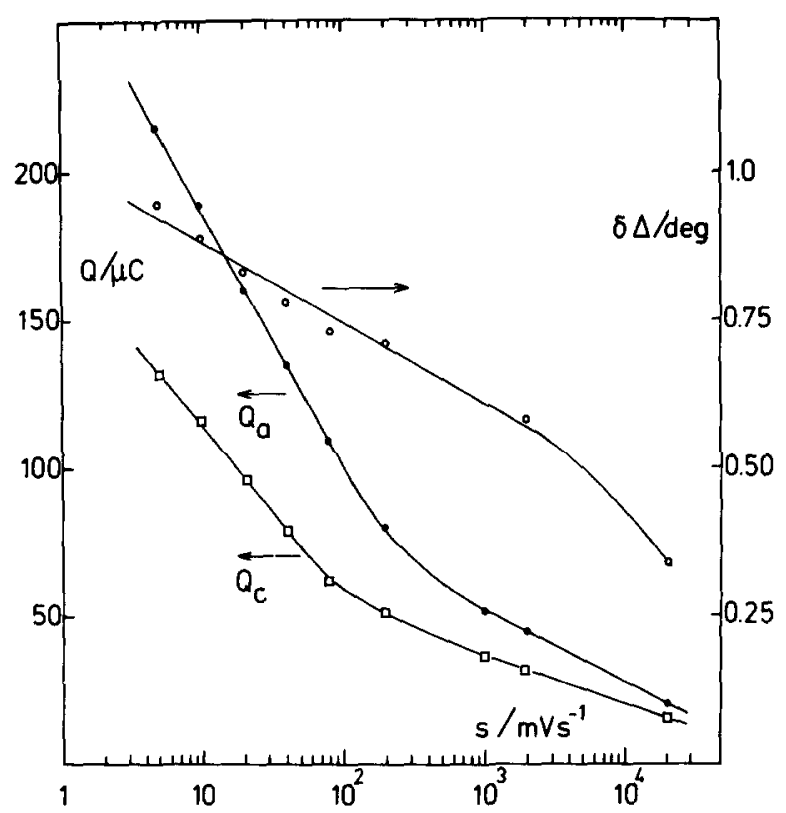

Fig. 7. $Q_{\mathrm{a}}, Q_{\mathrm{c}}$ and $\delta \Delta$ vs. sweep rate.

grams measured in these three solutions with $s=20 \mathrm{mV} \mathrm{s}^{-1}$ and $E_{\mathrm{u}}=180 \mathrm{mV}$.

Measurements in $1 \mathrm{M}, 10^{-1} \mathrm{M}, 10^{-2} \mathrm{M}$ and $10^{-3} \mathrm{M} \mathrm{NaOH}$ solutions showed a shift of both the anodic and the cathodic peaks in the voltammograms to higher potentials with decreasing hydroxide concentration. This shift amounted to about $40-50 \mathrm{mV}$ per $\mathrm{pH}$ unit. The same shift was observed for the $\delta \Delta / E$ curves.

\section{(3.2) Cyclic voltammetry with potential-scan arrest at the upper potential}

In cyclic voltammetry, the measured current is a complex function of both potential and time. To get more information about the influence of the latter parameter, potential scanning with a scan rate of $20 \mathrm{mV} \mathrm{s}^{-1}$ was applied as before, but this time the scan was arrested at various potentials $E_{\mathrm{u}}$ of sweep reversal, for $0,15,30$ and $60 \mathrm{~s}$. The results are shown in Fig. 8 and Table 1. Of the potentiodynamic curves with $E_{\mathrm{u}}=185 \mathrm{mV}$ only the curves with a scan arrest time of 0 and $15 \mathrm{~s}$ are given. At this potential a relatively large anodic current continues to flow and the cathodic charge during the negative sweep is much larger after the scan arrest of $15 \mathrm{~s}$ than in the normal cyclic voltammogram. At $185 \mathrm{mV}$ and higher potentials there is still considerable oxide formation. For instance at $250 \mathrm{mV}$, within 10 min a black surface film becomes visible. Upon reduction the silver colour returns, but the surface is severely roughened which is apparent from increased light scattering and larger currents in the following voltammogram. Also, it can be seen under the microscope that the whole surface has been "ploughed". The values of $\bar{\Delta}$ and $\bar{\psi}$ for this roughened silver are much lower than for the polished surfaces.

Table 1 shows that for potentials up to $125 \mathrm{mV}, Q_{\mathrm{c}}$ is larger for the curves with scan arrest than for those without. In contrast, $\delta \Delta$ is the same, whether or 


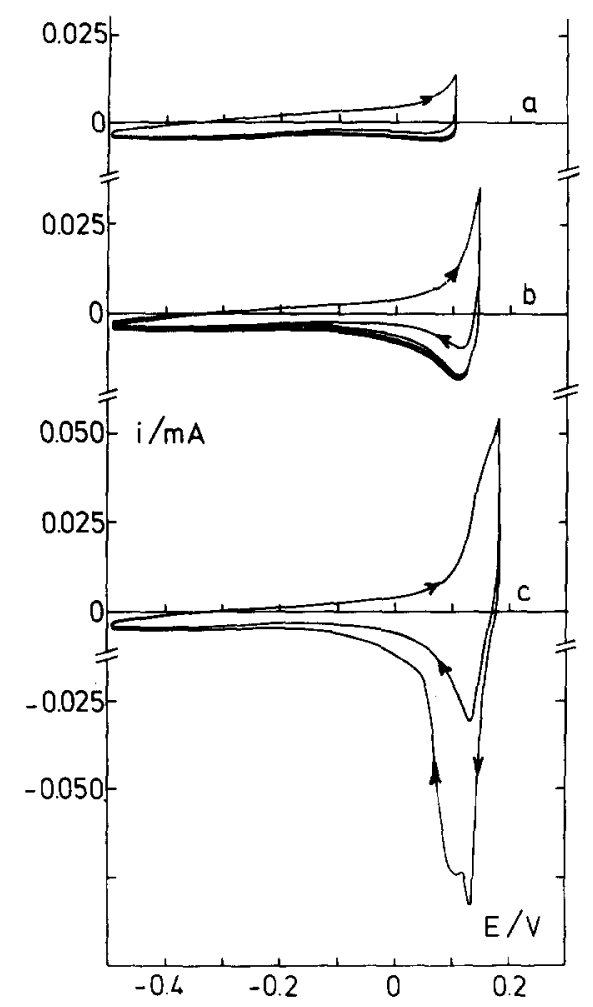

Fig. 8. Voltammograms with potential-scan arrest of $t$ seconds at the upper potential. $(\mathrm{a}, \mathrm{b}) t=0,15,30$ and $60 \mathrm{~s}$; (c) $t=0$ and $15 \mathrm{~s}$.

not the potential is arrested at $E_{\mathrm{u}}$. At 145 and $165 \mathrm{mV}$, both $Q_{\mathrm{c}}$ and $\delta \Delta$ increase in the first $15 \mathrm{~s}$ of waiting time. Thereafter there is still a small increase in $Q_{c}$, but $\delta \Delta$ remains almost the same. At $185 \mathrm{mV}, Q_{\mathbf{c}}$ as well as $\delta \Delta$ continue to increase strongly with waiting time.

Figure 8 shows that the peak potential of the cathodic wave hardly shifts with waiting time.

\section{TABLE 1}

Cathodic charge $Q_{c}(\mu \mathrm{C})$ and ellipsometric change $\delta \Delta(\mathrm{deg})$ with l.p.s.v. with scan arrest at $E_{\mathrm{u}}(\mathrm{mV})$ during $t$ seconds

\begin{tabular}{|c|c|c|c|c|c|c|c|c|}
\hline \multirow[t]{3}{*}{$E_{\mathbf{u}}$} & \multicolumn{8}{|l|}{$t$} \\
\hline & \multicolumn{2}{|l|}{$0 \mathrm{~s}$} & \multicolumn{2}{|l|}{$15 \mathrm{~s}$} & \multicolumn{2}{|l|}{$30 \mathrm{~s}$} & \multicolumn{2}{|l|}{$60 \mathrm{~s}$} \\
\hline & $Q_{c}$ & $\delta \Delta$ & $Q_{c}$ & $\delta \Delta$ & $Q_{\mathfrak{c}}$ & $\delta \Delta$ & $Q_{c}$ & $\delta \Delta$ \\
\hline $\begin{array}{l}105 \\
125\end{array}$ & $\begin{array}{l}15 \\
22\end{array}$ & $\begin{array}{l}0.34 \\
0.34\end{array}$ & $\begin{array}{l}29 \\
48\end{array}$ & $\begin{array}{l}0.34 \\
0.34\end{array}$ & $\begin{array}{l}29 \\
48\end{array}$ & $\begin{array}{l}0.34 \\
0.34\end{array}$ & $\begin{array}{l}29 \\
48\end{array}$ & $\begin{array}{l}0.34 \\
0.34\end{array}$ \\
\hline $\begin{array}{l}145 \\
165\end{array}$ & $\begin{array}{l}46 \\
81\end{array}$ & $\begin{array}{l}0.45 \\
0.60\end{array}$ & $\begin{array}{r}83 \\
133\end{array}$ & $\begin{array}{l}0.56 \\
0.83\end{array}$ & $\begin{array}{r}90 \\
142\end{array}$ & $\begin{array}{l}0.56 \\
0.84\end{array}$ & $\begin{array}{r}95 \\
153\end{array}$ & $\begin{array}{l}0.57 \\
0.86\end{array}$ \\
\hline 185 & 128 & 0.98 & 355 & $\geqslant 1.8$ & & & & \\
\hline
\end{tabular}




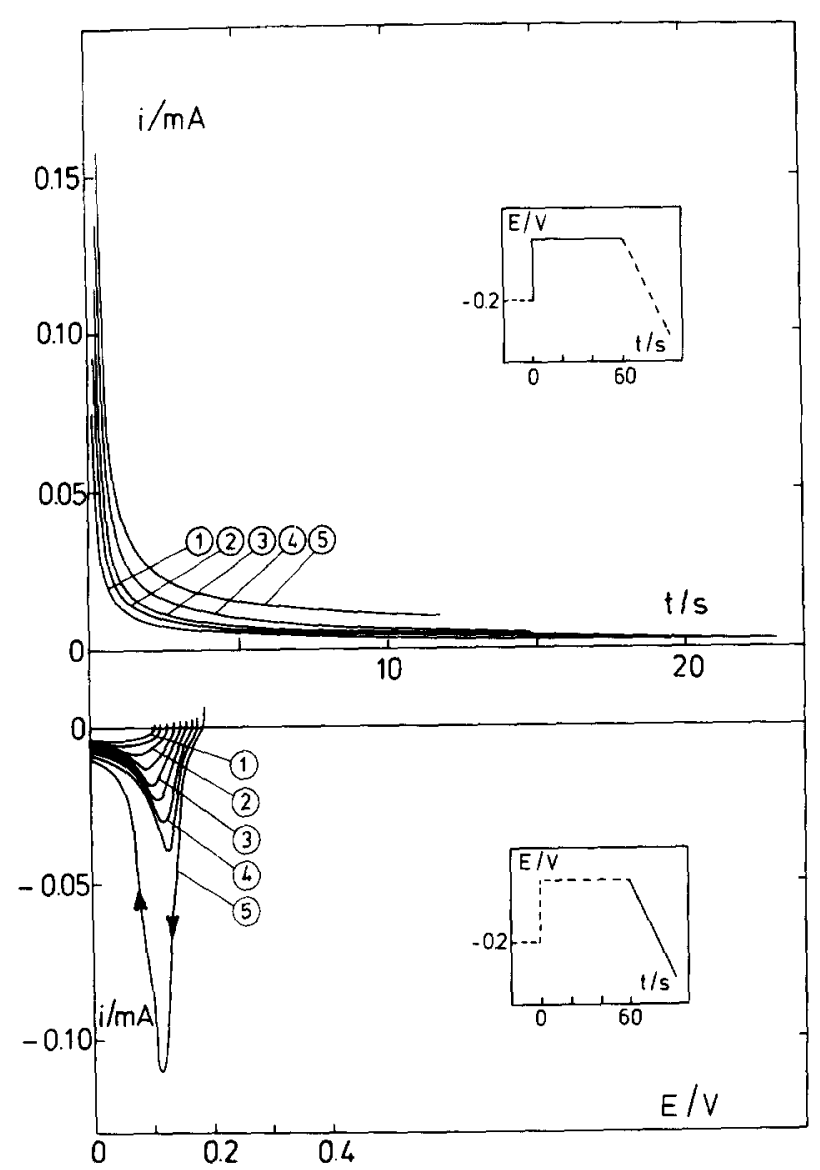

Fig. 9. (a) Potential step measurements, followed by (b) potentiodynamic reduction $(\mathrm{d} E / \mathrm{d} t=$ $20 \mathrm{mV} \mathrm{s}^{-1}$ ). (1) $E_{\mathrm{u}}=105 \mathrm{mV}$, (2) $E_{\mathrm{u}}=125 \mathrm{mV}$, (3) $E_{\mathrm{u}}=150 \mathrm{mV}$, (4) $E_{\mathrm{u}}=170 \mathrm{mV}$, (5) $E_{\mathrm{u}}=$ $190 \mathrm{mV}$.

\section{(3.3) Potential step measurements}

Potential step measurements make it possible to study directly the kinetics of the electrode reactions at a certain potential. In Fig. 9, current-time curves are shown which were measured upon stepping up the electrode potential from $-200 \mathrm{mV}$ to various potentials in the -100 to $+190 \mathrm{mV}$ region. After $60 \mathrm{~s} \mathrm{a}$ negative sweep was applied, with a scanning rate of $20 \mathrm{mV} \mathrm{s}^{-1}$, to analyse electrochemically the products formed during the potential step. Figure 10 shows several parameters plotted vs. the potential, namely $\delta \Delta$ upon anodisation, the peak potential $E_{\mathrm{p}}$ of the cathodic peak, the initial anodic current $\left(i_{\mathrm{i}}\right)$, the final current after $60 \mathrm{~s}\left(i_{\mathrm{f}}\right)$, and the charge $Q_{\mathrm{c}}$ under the cathodic peak. As in Fig. 4 the curves of $\delta \Delta, E_{\mathrm{p}}$ and $Q_{\mathrm{c}}$ show three distinct potential regions. In contrast the curve of $i_{\mathrm{i}}$ vs. $E$ does not show a sharp change near a potential of $190 \mathrm{mV}$. 


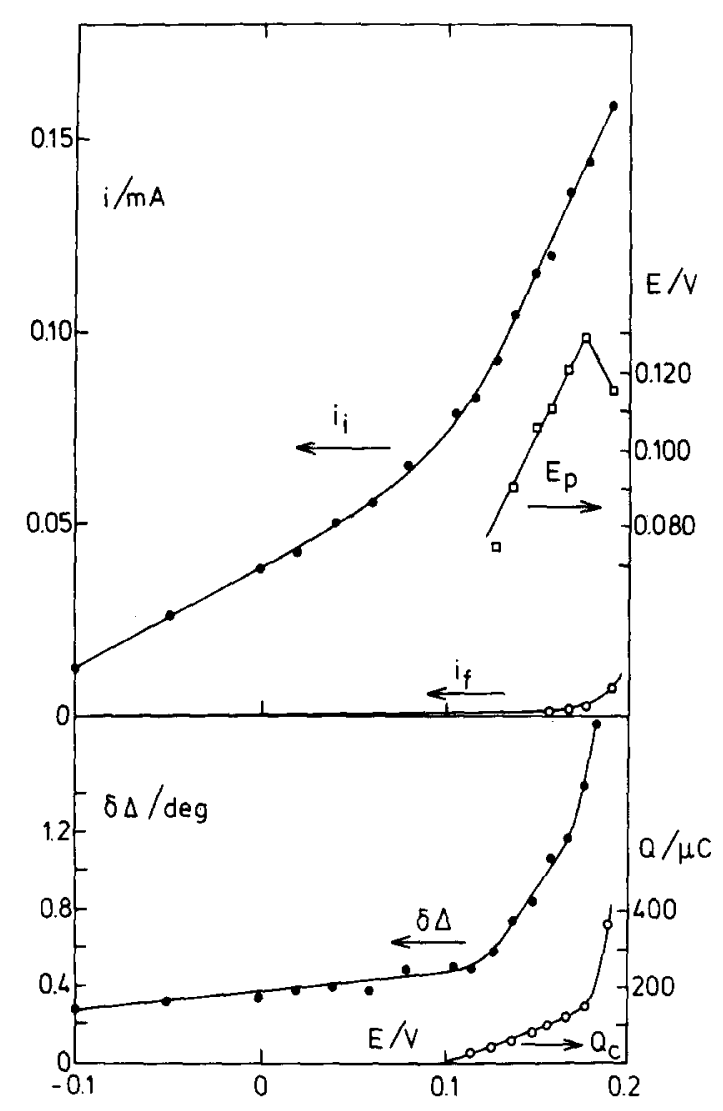

Fig. 10. $i_{\mathrm{i}}, E_{\mathrm{p}}, i_{\mathrm{f}}, \delta \Delta$ and $Q_{\mathrm{c}}$ plotted vs. $E_{\mathrm{u}}$ for the measurements shown in Fig. 9.

\section{(4) DISCUSSION}

In this study we were mainly interested in processes in the potential region of the A1 peak, the first anodic peak after the double layer region (see Fig. 1).

Concerning the second anodic peak (A2) the results of Section 3.2 show clearly that multilayer phase formation on the electrode is involved. The roughening upon reduction of this film is accompanied by a decrease in $\bar{\Delta}$ and $\bar{\psi}$, as found also for example by Kruger [40,41] for dissolution-roughening of iron and by Albers et al. [42] for ion bombardment induced damage in silver.

The invariance of the $\mathrm{A} 1$ peak potential with carbonate concentration proves that this peak cannot be due to carbonate impurities; this contradicts earlier suggestions $[22,23]$.

In all our experiments the $\mathrm{Al}$ peak was found, provided the electrode surface was sufficiently cleaned. The fact that Stonehart and Portante [16] did not find the A1 peak when they oxidized electroplated silver can probably be explained by cyanide contamination of the surface. Alternatively it cannot be excluded that the reaction is plane-specific, and that there was a large difference in crystal-plane distribution between the mechanically polished and the electroplated electrodes used. In the region of the A1 peak the $i / E$ curves show upon sweep reversal an immediate fall of the current, and the peak potentials 
depend only slightly on the sweep rate in the $0.005-2 \mathrm{~V} \mathrm{~s}^{-1}$ range. Both phenomena indicate that the oxidation corresponding to this peak has the characteristics of a reversible process. In the cyclic voltammograms reaching just into the A2 peak region, the observed continuation of anodic current in the initial part of the cathodic sweep indicates an irreversible process.

Figures 3 and 4 show that at a scan rate of $20 \mathrm{mV} \mathrm{s}^{-1}$ in the Al region a charge is transferred that is several times larger than that required to form a monolayer of $\mathrm{Ag}_{2} \mathrm{O}$ ( $220 \mu \mathrm{C} \mathrm{cm}^{-2}$ for the $\mathrm{Ag}(111)$ face).

A graph similar to Fig. 4 recently led Kudryavtseva et al. [43] to the conclusion that their $\delta \Delta$ measurements were in good agreement with the data of their electrochemical measurements. However, this conclusion is very premature, as - for example - follows from a comparison of the Figs. 3 and 5. Although the $Q / E$ and $\delta \Delta / E$ curves are similar, the exact shapes differ. In the reduction curve $\delta \Delta$ has returned to the value it had before oxidation, at a potential of about $100 \mathrm{mV}$, whereas the reduction peak in the voltammogram is not yet completed at this potential. Evidently part of the electrochemical process is "invisible" for the ellipsometric measurement. In Fig. 7 it can be seen that $\delta \Delta$ is not proportional to the charges $Q_{\mathbf{a}}$ or $Q_{\mathrm{c}}$. Also from the scan arrest results in Table 1 it is clear that charge is not always accompanied by changes in $\delta \Delta$.

In the current-voltage curves every electron transferred across the metal-electrolyte interface is counted. So the difference between the electrochemical and the ellipsometric results indicates that the A1 peak represents a complex process, consisting of at least two reactions, one of which is much more easily detected by ellipsometry than the other.

In the $\mathrm{A} 1$ peak region no detectable surface roughening occurs; from the first sweep the current-voltage curves remain the same, as do the parameters $\bar{\Delta}$ and $\bar{\psi}$.

The optical constants found for the clean silver compare reasonably with the literature data of Kudryavtseva et al. [43] who give for the same wavelength $n=0.38 \pm 0.02$ and $k=3.71 \pm 0.01$. As could be expected for the polycrystalline material, the optical constants differ somewhat from the values obtained by Albers et al. [42] for carefully annealed single crystals in an ultra high vacuum environment $(n=0.054 \pm 0.01$ and $k=4.54 \pm 0.10)$.

Ambrose and Barradas [27] have shown with ring disc experiments that in the A1 peak region dissolution of silver species occurs. One would expect such a dissolution reaction to be limited by diffusion away from the electrode of soluble $\mathrm{Ag}(\mathrm{I})$ species. The first three voltammograms in Fig. 2 have the same overall shape as the curves for a dissolution reaction, as simulated by Casadio [44] and Barradas et al. [45], and measured by the latter at lead amalgam electrodes in $\mathrm{HCl}$ solutions [45]. For a diffusion controlled process one would expect the peak current density $i_{\mathrm{p}}$ to depend linearly on the square root of the scanning rate. This, however, is not the case, so probably an adsorption process - for which $i_{\mathrm{p}}$ is proportional to $s-$ is also involved. It is reasonable to assume that this surface process is the one that is measured ellipsometrically.

Adsorption is expected to dominate the voltammogram increasingly with increasing scan rate. This is exactly what is seen in Fig. $7 ; \delta \Delta$ decreases much more slowly with increasing scan rate than $Q$, i.e. an increasing fraction of the 


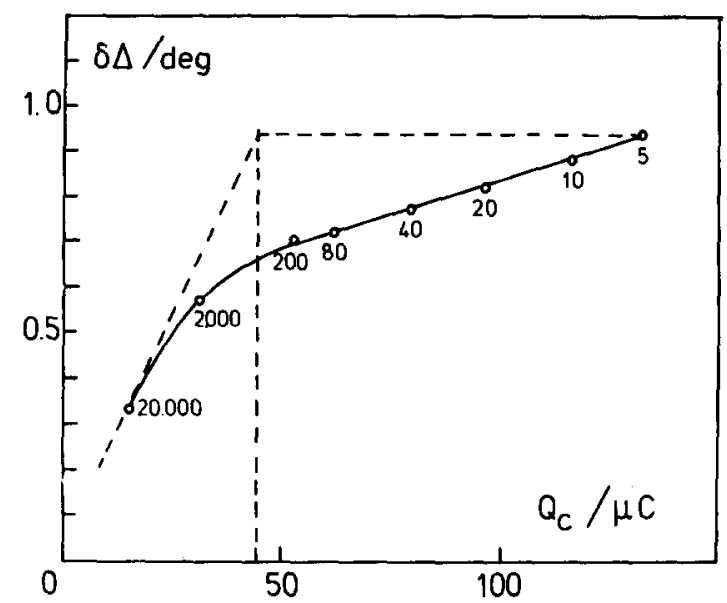

Fig. 11. $\delta \Delta$ vs. $Q_{\mathrm{c}}$ for voltammograms taken with different sweep rates. Numbers in the Figure indicate sweep rates in $\mathrm{mV} \mathrm{s}^{-1}$. Double layer contributions to $\delta \Delta$ and $Q_{\mathrm{c}}$ are taken to be $0.2 \mathrm{deg}$ and $8 \mu \mathrm{C}$, respectively.

total current must be ascribed to chemisorption of oxygen. At the highest sweep rates used ( 1 to $20 \mathrm{~V} \mathrm{~s}^{-1}$ ) the charges are of the order of magnitude of that required for monolayer formation.

Figure 11 gives the relation between $\delta \Delta$ and $Q_{\mathrm{c}}$ at various sweep rates. At the highest sweep rates the contribution of the dissolution process is low, and consequently, the slope of the $\delta \Delta / Q_{\mathrm{c}}$ curve has its maximum value there. This initial slope permits us to make a rough estimate of the dependence of $\delta \Delta$ on the charge accompanied by surface layer formation. The highest $\delta \Delta$ of about $0.95^{\circ}$ corresponds to circa $40 \mu \mathrm{C}$, which is roughly the charge expected for monolayer formation. The scan arrest measurements do not show any shift of the cathodic current peak, so an "ageing" process such as that reported for oxygen chemisorption on platinum and gold electrodes [46-48] was not found. For potentials up to $125 \mathrm{mV}$ there is no further change in $\delta \Delta$ upon arresting the potential scan (see Table 1). Thus the oxide formation is fast and no further oxide is formed during the scan arrest. Dissolution continues, as can be seen from the larger cathodic charge when the scan is arrested. At 145 and $165 \mathrm{mV}$ the change in $\Delta$ continues during the first seconds of scan arrest. But, within $15 \mathrm{~s}$ a saturation value is reached, so the further increase of $Q_{\mathrm{c}}$ with longer waiting times does not correspond to further changes in surface coverage.

From the scan arrest measurements, as well as from the potential step measurements, it is clear that in the A1 region the equilibrium surface coverage is potential-dependent.

The current-time curves in Fig. 9 are monotonical falling curves. This points to a process of random electrodeposition, since a mechanism of nucleation and growth would lead to a characteristic peak in the $i-t$ profile [49]. The same conclusion can be drawn from the current-voltage curves in Fig. 2, where, upon reversal of the sweep in the first part of the $\mathrm{A} 1$ peak there is never a continuing increase of current [50]. The initial part of the $i-t$ curve at $190 \mathrm{mV}$ (Fig. 9) is not essentially different from the other curves. This means that first a surface film is formed which is then followed by in-depth oxidation. 
The potential dependence of the surface coverage may be explained by surface heterogeneity. Certainly our mechanically polished, polycrystalline silver surfaces are composed of many different crystal planes. The various adsorption sites can be expected to have different energies and the number of active sites will vary with potential.

Our objective is to perform measurements on single crystal surfaces, and to compare the electrochemical oxidation with studies of oxygen chemisorption from the gas phase, where a great difference in reactivity was found between the $\mathrm{Ag}(111)$ and the $\mathrm{Ag}(110)$ surface $[51,52]$. Preliminary experiments in the A1 region showed strikingly different voltammograms for the $\mathrm{Ag}(111)$ and the $\mathrm{Ag}(110)$ faces, with the $\mathrm{Ag}(110)$ face indeed being the most reactive one.

Giles et al. [29,30] and Ambrose and Barradas [27] have proposed that the dissolution of silver occurs as the soluble ion $\mathrm{Ag}(\mathrm{OH})_{2}^{-}$according to

$\mathrm{Ag}+2 \mathrm{OH}^{-} \rightleftharpoons \mathrm{Ag}(\mathrm{OH})_{2}^{-}+e$

However, the equilibrium-potential/pH dependence for this reaction is given by $E_{0}(\mathrm{~V})=$ constant $-0.118 \mathrm{pH}+0.059 \log \left[\mathrm{Ag}(\mathrm{OH})_{2}^{-}\right]$

Since the A1 peak does not shift $120 \mathrm{mV}$ per $\mathrm{pH}$ unit, but shifts even less than $60 \mathrm{mV}$ (Section 3.1.3) reaction (1) does not describe the dissolution.

\section{(5) CONCLUSION}

Our combined electrochemical and ellipsometric measurements indicate that in the initial (A1) stage of the anodic oxidation of silver in a $\mathrm{NaOH}$ solution two processes occur, namely the dissolution of silver species and the formation of a monolayer of surface oxide. The second stage (A2) involves the formation of multilayer oxide.

\section{REFERENCES}

1 T.P. Dirkse, J. Electrochem. Soc., 106 (1959) 453.

2 L. Young, Anodic Oxide Films, Academic Press, London, 1961, pp. 302-307.

3 J.A. McMillan, Chem. Rev., 62 (1962) 65.

4 J.A. Allen, Proc. 1st Australian Conference on Electrochemistry, Pergamon, Oxford, 1965, pp. 76-87.

5 C. Vanleugenhaghe, M. Pourbaix and P. Van Rysselberghe in M. Pourbaix (Ed.), Atlas of Electrochemical Equilibria in Aqueous Solutions, Pergamon Press, London, 1966, pp. 393-398.

6 J.P. Hoare, The Electrochemistry of Oxygen, Interscience, New York, 1968, pp. 211-238.

7 L.M. Gedansky and L.G. Hepler, Engelhard Ind. Tech. Bull., 9 (1969) 117.

8 A. Fleischer and J.J. Lander (Eds.), Zinc-Silveroxide Batteries, John Wiley, New York, 1971, pp. 99179.

9 N.A. Hampson, J.B. Lee and J.R. Morley, Electrochim. Acta, 16 (1971) 637.

10 Gmelins Handbuch der Anorganische Chemie, Part B1, 8th edn., 1971, pp. 125-134.

11 S. Toshima, Progr. Surf. Membr. Sci., 4 (1971) 231.

12 Gmelins Handbuch der Anorganische Chemie, Part A4, 8th edn., 1974, pp. 243-279.

13 T.P. Dirkse and D.B. de Vries, J. Phys. Chem., 63 (1959) 107.

14 M.R. Tarasevich, N.A. Shumilova and R.K. Burshtein, Izv. Akad. Nauk SSSR, 1 (1964) 14.

15 P. Stonehart, Electrochim. Acta, 13 (1968) 1789.

16 P. Stonehart and F.P. Portante, Electrochim. Acta, 13 (1968) 1805.

17 H. Göhr and A. Breitenstein, Electrochim. Acta, 13 (1968) 1377.

18 T.G. Clarke, N.A. Hampson, J.B. Lee, J.R. Morley and B. Scanlon, Can. J. Chem., 46 (1968) 3437.

19 T.G. Clarke, N.A. Hampson, J.B. Lee, J.R. Morley and B. Scanlon, Ber. Bunsenges. Phys. Chem., 73 (1969) 279. 
20 R. Memming, F. Möllers and G. Neumann, J. Electrochem. Soc., 117 (1970) 451.

21 B. Miller, J. Electrochem. Soc., 117 (1970) 491.

22 B.V. Tilak, R.S. Perkins, H.A. Kozlowska and B.E. Conway, Electrochim. Acta, 17 (1972) 1447.

23 R.S. Perkins, B.V. Tilak, B.E. Conway and H.A. Kozlowska, Electrochim. Acta, 17 (1972) 1471.

24 T. Yoshimura and M. Yamashita, Doshisha Daigaku Rikogaku Kenkyu Hokoku, 13 (1973) 204.

25 N.A. Hampson, K.I. MacDonald and J.B. Lee, J. Electroanal. Chem., 45 (1973) 149.

26 N. Sato and Y. Shimizu, Electrochim. Acta, 18 (1973) 567.

27 J. Ambrose and R.G. Barradas, Electrochim. Acta, 19 (1974) 781.

28 M. Březinà, J. Koryta and M. Musilová, Collect. Czech. Chem. Commun., 33 (1968) 3397.

29 R.D. Giles, J.A. Harrison and H.R. Thirsk, J. Electroanal. Chem., 22 (1969) 375.

30 R.D. Giles and J.A. Harrison, J. Electroanal. Chem., 27 (1970) 161.

31 R.M.A. Azzam and N.M. Bashara, J. Opt. Soc. Amer., 61 (1971) 600.

32 R.M.A. Azzam and N.M. Bashara, J. Opt. Soc. Amer., 61 (1971) 773.

33 A.K.N. Reddy and B. Rao, Can. J. Chem., 47 (1969) 2687.

34 Y.C. Chiu and M.A. Genshaw, J. Phys. Chem., 73 (1969) 3571.

35 J.J. Carroll and A.J. Melmed, Surface Sci., 16 (1969) 251.

36 G. Valette and A. Hamelin, J. Electroanal. Chem., 45 (1973) 301.

37 T.E. Furtak and D.W. Lynch, J. Electroanal. Chem., 79 (1977) 1.

38 T.E. Furtak, J. Phys., 38 (1977) C5-233.

39 D. Ross and E.F.I. Roberts, Electrochim. Acta, 21 (1976) 371.

40 J. Kruger, Corrosion, 22 (1966) 88.

41 J. Kruger, J. Phys., 38 (1977) C5-129.

42 H. Albers, J.M.M. Droog and G.A. Bootsma, Surface Sci., 64 (1977) 1.

43 Z.I. Kudryavtseva, N.A. Shumilova, V.A. Openkin, N.A. Zhuchkova and E.I. Krushcheva, Soviet Electrochem., 13 (1977) 608.

44 S. Casadio, J. Electroanal. Chem., 67 (1976) 126.

45 R.G. Barradas, S. Fletcher and J.D. Porter, J. Electroanal. Chem., 80 (1977) 295.

46 H. Angerstein-Kozlowska, B.E. Conway and W.B.A. Sharp. J. Electroanal. Chem., 43 (1973) 9.

47 N.R. de Tacconi, A.J. Calandra and A.J. Arvía, J. Electroanal. Chem., 51 (1974) 25.

48 C.M. Ferro, A.J. Calandra and A.J. Arvía, J. Electroanal. Chem., 59 (1975) 235.

49 H. Angerstein-Kozlowska, B.E. Conway and J. Klinger, J. Electroanal. Chem., 87 (1978) 321.

50 H. Angerstein-Kozlowska, B.E. Conway and J. Klinger, J. Electroanal. Chem., 87 (1978) 301.

51 H. Albers, W.J.J. van der Wal and G.A. Bootsma, Surface Sci., 68 (1977) 47.

52 H. Albers, W.J.J. van der Wal, O.L.J. Gijzeman and G.A. Bootsma, Surface Sci., 77 (1978) 1. 